\title{
Howard A. Reber, M.D., Distinguished Professor of Surgery, UCLA School of Medicine
}

\author{
O. Joe Hines
}

Received: 7 March 2010 / Accepted: 9 March 2010/Published online: 10 April 2010

(C) The Author(s) 2010. This article is published with open access at Springerlink.com

Dr. Howard A. Reber was born in Philadelphia, Pennsylvania, on March 31, 1938. He was raised in Pennsylvania and attended Temple University, obtaining a degree in chemistry in 1959. Following graduation, he enrolled at the prestigious University of Pennsylvania School of Medicine. As a third year medical student, Dr. Reber became fascinated with the physiology and function of the pancreas - an interest that would fuel many future accomplishments. He had always known that he wanted to be a surgeon, and he remained at the University of Pennsylvania to complete his surgical training in 1970. During residency, he began his research career as a National Institutes of Health fellow under the direction of Drs. Jonathan E. Rhoads and Frank P. Brooks. This experience ignited a commitment to scientific discovery that has defined his entire career.

Following his surgical training and accompanied by his wife, Elaine, Dr. Reber moved from Philadelphia to Midwest City, Oklahoma, where he completed 2 years of military service at Tinker Air Force Base. After fulfilling this obligation, the Rebers moved to San Francisco, where Howard spent 6 years as a member of the surgical faculty at the University of California. While at UCSF, Dr. Reber began to establish his clinical expertise in diseases of the pancreas under the mentorship of Dr. Lawrence Way. In 1978, he was recruited to the University of Missouri, where he served as the Chief of Surgery at the Truman Veterans Administration Medical Center.

In 1986, Dr. Reber moved to the University of California, Los Angeles. He was recruited to the position of Chief of Surgery at the Sepulveda Veterans Administra-

O. J. Hines $(\bowtie)$

School of Medicine, UCLA,

Los Angeles, CA, USA

e-mail: joehines@mednet.ucla.edu tion Medical Center and then became the fulltime Chief of Gastrointestinal Surgery at UCLA. His administrative duties have included serving as Department Vice Chairman, Chief of the Division of General Surgery, Department Director of Education, and Co-director of the Surgery Residency Training Program. In recent years, he has devoted a significant portion of his administrative time to faculty appointments and promotions and recently completed a term as the Chair of the Council on Academic Personnel for the entire UCLA campus. His current position is Distinguished Professor of Surgery, Chief of Gastrointestinal Surgery, and Director of the Center for Pancreatic Disease at UCLA.

Dr. Reber has had an important international leadership role in surgery. He is a member of all major learned surgical societies, including the American Surgical Association, Society of Clinical Surgery, Society of University Surgeons, American Gastroenterological Association, Society of Surgical Oncology, and American Society of Clinical Oncology. He has served as the President and, for nearly 20 years, Secretary-Treasurer of the American Pancreatic Association. He was elected as Vice President of the Society for Surgery of the Alimentary Tract and is a member of its Board of Trustees.

Dr. Reber has established a world renowned surgical practice focused on pancreatic diseases and has accumulated a vast experience with the entire breadth and depth of the discipline. Clearly recognized as one of the top five pancreatic surgeons in the world, he has lectured throughout North America, Asia, and Europe. He was awarded the Vay W. Liang and Frisca Go Award for Lifetime Achievement in Pancreatology and has been a named lecturer at Johns Hopkins, Brigham and Women's Hospital, and the Mayo Clinic. 
Dr. Reber has conducted pioneering research in both benign and malignant pancreatic diseases. As a young investigator, he performed basic physiologic studies regarding the role of the pancreatic ductal epithelium in pancreatic electrolyte secretion. He then became interested in acute pancreatitis and developed a concept that became known as the pancreatic duct mucosal barrier. This work established the concept that a variety of substances could increase ductal permeability and produce acute pancreatitis. He next took up the problems of chronic pancreatitis, developing the hypothesis that the gland was severely ischemic in this disease and that this ischemia was responsible for the severe pain that characterized the disease. Over the past decade, he has focused his work on pancreatic cancer and has developed and directs a multifaceted translational research program at UCLA, supported by the Hirshberg Foundation. Dr. Reber's research has been continuously funded by the National Institutes of Health, Veterans Administration, and the National Cancer Institute since 1972. He is the author of more than 220 scientific manuscripts and 92 book chapters and the editor of eight books. He serves on the editorial board of six medical journals. His textbook, Pancreatic Cancer: Pathogenesis, Diagnosis and Treatment, is a comprehensive and frequently referenced review.

Dr. Reber has been an inspired mentor for a long list of trainees. His laboratory has hosted young surgical scientists from around the world. More than 40 investigators have worked under his direction and have benefited from his consistent and linear approach to scientific discovery. Moreover, he has trained dozens of surgical residents in gastrointestinal and pancreatic surgical techniques. Residents uniformly agree that the rotation with Dr. Reber in the chief year is the most enjoyable of the residency and identify the time with him in the operating room as the pinnacle of their surgical training.

Dr. Reber has exceptional devotion to his family. Elaine, his loving wife of almost 50 years, has stood shoulder to shoulder with him and has pursued her own career as a leader in information technology at UCLA and the California Institute of Technology. The Rebers have four children, David, Susan, Donna, and Kenny, and the Reber clan has now grown to include eleven beautiful grandchildren. Grandpa and Grandma Reber have remained intimately involved in their grandchildren's lives and regularly attend school events, graduations, and birthdays. Elaine and Howard make a wonderful couple and have set a standard as parents and grandparents that each of us should strive to emulate.

Dr. Reber is an exceptional physician, revered by patients and highly respected by peers. His devotion to the doctorpatient relationship is well known, and he sets a tremendous example for colleagues, residents, and students each day. I have been immensely fortunate to know him and greatly advantaged by his example and his wise counsel. Anyone who spends time with Dr. Reber soon recognizes the central importance of truth, consistency, empathy, professionalism, medical expertise, and technical skill in the mastery of surgery that have characterized his entire career.

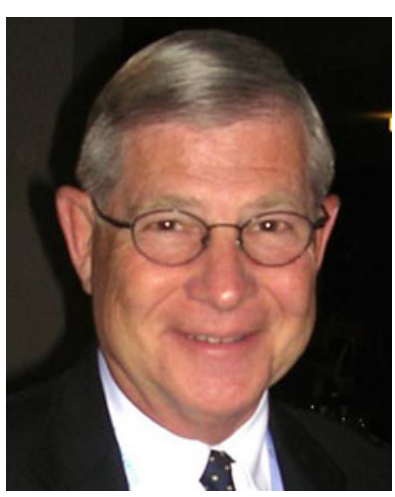

Dr. Howard A. Reber

Open Access This article is distributed under the terms of the Creative Commons Attribution Noncommercial License which permits any noncommercial use, distribution, and reproduction in any medium, provided the original author(s) and source are credited. 